\title{
Caracterização da madeira serrada em clones de Eucalyptus
}

\author{
Israel Luiz de Lima1*, José Luiz Stape ${ }^{2}$ \\ ${ }^{1}$ Instituto Florestal do Estado de São Paulo, Rua do Horto, 931, CEP 02337-000, São Paulo, SP, Brasil \\ ${ }^{2}$ Suzano Papel e Celulose, Rod. Br 101, Km 945,5, s/n, CEP 45930-000, Mucuri, BA, Brasil
}

"Autor correspondente:

limailde@gmail.com

Termos para indexação:

Produto florestal

Defeito da madeira

Tensão de crescimento

Index terms:

Timber

Wood defects

Growth stresses

Histórico do artigo:

Recebido em 25/11/2015

Aprovado em 11/03/2017

Publicado em 31/03/2017

doi: $10.4336 / 2017 . p f b .37 .89 .1113$

\begin{abstract}
Resumo - O objetivo desse trabalho foi caracterizar a madeira serrada de clones de Eucalyptus com 7 a 13 anos, plantados comercialmente na região de Entre Rios e Esplanada, BA. Para efeito de comparação e como referência, foram utilizadas amostras de Eucalyptus cloeziana com 22 anos, em função da ótima aptidão dessa espécie para serraria. As amostras foram retiradas em duas posições verticais e três posições radiais ao longo do tronco das árvores. Foram observadas diferenças entre clones e posição radial para o índice de rachaduras de extremidade de tábuas secas, flecha de encurvamento, flecha de arqueamento e quantidade de nós, enquanto não houve diferenças em relação à posição da tora ao longo do fuste. Todos os materiais apresentaram alta incidência de nós. As rachaduras de tábua seca, arqueamento e quantidade de nós diminuem no sentido medula-casca, enquanto que o encurvamento tende a aumentar.
\end{abstract}

\section{Characterization of sawn wood of Eucalyptus clones}

\begin{abstract}
The object of this work was to characterize sawn wood of Eucalyptus clones with 7 to 13 years old planted on Entre Rios and Esplanada regions, Bahia State. For comparison and reference Eucalyptus cloeziana samples with 22 years old were used, as this species present great saw timber potential. Samples were taken along trees trunks on two vertical and three radial positions. Differences were observed among clones and radial position for end splitting of dry lumber, bowing and bending indexes, and number of knots although there was no evidence of difference due to log position along the trunk. All materials presented high incidence of knots. End splitting of the dry lumber and bending indexes and number of knots decreased from pith to bark, while bowing tended to increase.
\end{abstract}

\section{Introdução}

Algumas espécies de árvores do gênero Eucalyptus apresentam rápido crescimento e boa adaptação às condições ambientais encontradas em grande parte do Brasil. Entre essas há espécies e clones com potencial para processamento mecânico, com boas propriedades físicas e mecânicas e de fácil trabalhabilidade, o que possibilita a obtenção de madeira desdobrada com baixo custo de produção.
A exemplo de outros países, no Brasil os novos materiais genéticos de espécies e híbridos de Eucalyptus (clones ou sementes) existentes em ensaios experimentais, ou em plantações comerciais, precisam ser testados quanto às aptidões para desdobro e uso como madeira sólida. Entretanto, tais pesquisas não são rotineiramente efetuadas, pois o setor de madeira serrada de Eucalyptus não é tão grande e organizado quanto o setor de celulose ou carvão e, além disso, o tempo de maturação dos materiais é rápido. 
Algumas espécies do gênero Eucalyptus, quando utilizadas para a produção de madeira serrada, podem apresentar características que dificultam o seu uso. Essas dificuldades não são, todavia, maiores do que aquelas apresentadas pela maioria das madeiras (Ponce, 1995). As principais características que causam baixos rendimentos na produção de madeira serrada são as rachaduras, os empenamentos, presença de madeira juvenil, ocorrência de retração, colapso, nós e bolsas de resina e variabilidade em suas propriedades (Freitas \& Brito Neto, 1993; Viana, 1996).

As rachaduras e empenamentos são os principais defeitos, que são originários das elevadas tensões de crescimento nas árvores. Esses defeitos ocorrem devidos à liberação das tensões residuais nas toras. Essas tensões são definidas como forças que se desenvolvem no interior dos troncos das árvores vivas. As tensões ocorrem nas árvores antes da derrubada, atuando como uma forma de proporcionar estabilidade e manter o equilíbrio (Dinwoodie, 1966; Van Wik, 1978). Para Jacobs (1945), essas tensões são características intrínsecas ao crescimento natural das árvores e podem ocorrer tanto em folhosas como em coníferas. As causas das altas tensões de crescimento nas árvores não são bem conhecidas, mas acredita-se que estejam relacionadas a fatores genéticos, idade, dimensões da tora, taxa de crescimento e inclinação do fuste (Opie et al., 1984),

Após a derrubada das árvores e o traçamento do tronco ocorre a liberação das tensões de crescimento, que são aliviadas parcialmente, ocasionando a maioria das rachaduras de topo de tora. Estas podem se estender durante uma semana após o corte. Entretanto, rachaduras adicionais podem ocorrer durante o desdobro, quando há encurvamento longitudinal das peças devido às tensões residuais ao longo da tora. Essas rachaduras ou fendas podem ser intensas, podendo ser acentuadas durante a secagem. Portanto, as tensões de crescimento podem causar defeitos que forçam a redução das dimensões das peças obtidas, principalmente o comprimento (Opie et al., 1984; Kubler, 1987; Malan \& Hoon, 1992).

Muitos estudos foram desenvolvidos nos últimos anos, tentando entender e quantificar, essas rachaduras e empenamentos. Uma linha de pesquisa a ser seguida é a seleção de material com menores níveis de tensão de crescimento, e a associação desses às características facilmente mensuráveis, que devem ser priorizadas em programas de melhoramento genético florestal de espécies do gênero Eucalyptus (Carvalho et al., 2010).
Segundo Duque Silva et al. (2012), variações nas rachaduras ocorrem tanto em nível de espécies quanto de procedências e de indivíduos, sendo que o mais importante é que a participação de fatores genéticos na expressão dessa característica explica a maior parte das variações observadas, indicando que a seleção pode, efetivamente, produzir alterações positivas no sentido de redução das rachaduras em madeiras de Eucalyptus.

O objetivo desse trabalho foi caracterizar a madeira serrada de clones de Eucalyptus de 7 a 13 anos, plantados comercialmente na região de Entre Rios e Esplanada, na Bahia, tendo como referência E. cloeziana, com 22 anos.

\section{Material e métodos}

As amostras foram coletadas em diferentes populações experimentais de clones de espécies de Eucalyptus urophylla (Tabela 1). A origem do material em estudo é da região de Esplanada e Entre Rios, BA. O Município de Esplanada localiza-se a 11047'46"'S e $37^{\circ} 56^{\prime} 42^{\prime \prime} \mathrm{W}$, a 142 m de altitude, e Entre Rios localiza-se a 11056'31'S e longitude $38^{\circ} 05^{\prime} 04^{\prime \prime} \mathrm{W}$, a $162 \mathrm{~m}$ de altitude. O clima na região é predominantemente tropical, com temperaturas elevadas e médias anuais que ultrapassam os $26^{\circ} \mathrm{C}$. Há distinções quanto aos índices de precipitação em cada região, sendo que no litoral e na região de Ilhéus, a umidade é maior e a precipitação pode ultrapassar os $1.500 \mathrm{~mm}$ anuais e no sertão pode não alcançar $500 \mathrm{~mm}$ (Apolo11, 2016).

Tabela 1. Clones de Eucalyptus spp. selecionados para o estudo de desdobro.

\begin{tabular}{ccccc}
\hline Tratamento & Clone & $\begin{array}{c}\text { Idade } \\
\text { (anos) }\end{array}$ & $\begin{array}{c}\text { DAP } \\
(\mathbf{c m})\end{array}$ & $\begin{array}{c}\text { Altura } \\
\text { total } \\
(\mathbf{m})\end{array}$ \\
\hline 1 & COP1277 & 10 & 34,7 & 28,1 \\
2 & COP1249 & 8 & 31,7 & 30,2 \\
3 & COP1341 & 13 & 29,3 & 35,5 \\
4 & COP2361 & 10 & 33,8 & 38,6 \\
5 & COP2361D & 10 & 32,7 & 37,5 \\
6 & COP0477 & 10 & 33,5 & 42,1 \\
7 & COP7490 & 9 & 28,6 & 29,9 \\
8 & COP0321 & 9 & 28,7 & 29,8 \\
9 & COP1404 & 8 & 35,4 & 40,7 \\
10 & COP1406 & 8 & 31,5 & 36,0 \\
11 & COP1296 & 8 & 29,9 & 36,7 \\
12 & COP0520 & 7 & 24,2 & 30,1 \\
13 & E. cloeziana & 22 & 34,0 & 30,2 \\
\hline
\end{tabular}

Sendo: DAP = diâmetro a $1,30 \mathrm{~m}$ do solo.

Foram avaliadas árvores adultas (7 a 13 anos) de material clonal de Eucalyptus, que estão apresentando 
crescimento promissor em testes clonais em novas regiões de plantio em alguns estados do Brasil, tais como MS, MT, PA e BA. Esse estudo permite conhecer a variabilidade de aptidão para desdobro de material selecionado para produção de biomassa e, simultaneamente, é possível conhecer o seu potencial para serraria. Para efeito de comparação e referência foi utilizado Eucalyptus cloeziana, espécie com ótima aptidão para serraria, com 22 anos.

Inicialmente, foi realizado inventário das áreas de plantio, e a partir da distribuição diamétrica foi definida a classe de DAP (diâmetro a 1,30 $\mathrm{m}$ do solo) mediana de cada população (Tabela 1). Em cada parcela foram selecionadas quatro árvores, devidamente identificadas em campo. De cada árvore selecionada, foram retiradas duas toras de $3 \mathrm{~m}$ de comprimento, sendo a $1^{\text {a }}$ tora retirada na base da árvore e a $2^{\mathrm{a}}$ tora, a subsequente. As toras foram utilizadas para avaliações dos defeitos oriundos da tensão de crescimento e tensão de secagem na madeira serrada.

$\mathrm{O}$ desdobro das $1^{\text {as }}$ e $2^{\text {as }}$ toras foi realizado em uma serraria comercial, segundo a estratégia de desdobro esquematizada e adotada pela empresa na produção de peças serradas de dimensões comerciais. Essa operação foi efetuada durante a primeira semana após a derrubada das árvores. A espessura da tábua (h) foi fixada em 2,5 $\mathrm{cm}$ e a largura (b) em $12 \mathrm{~cm}$.

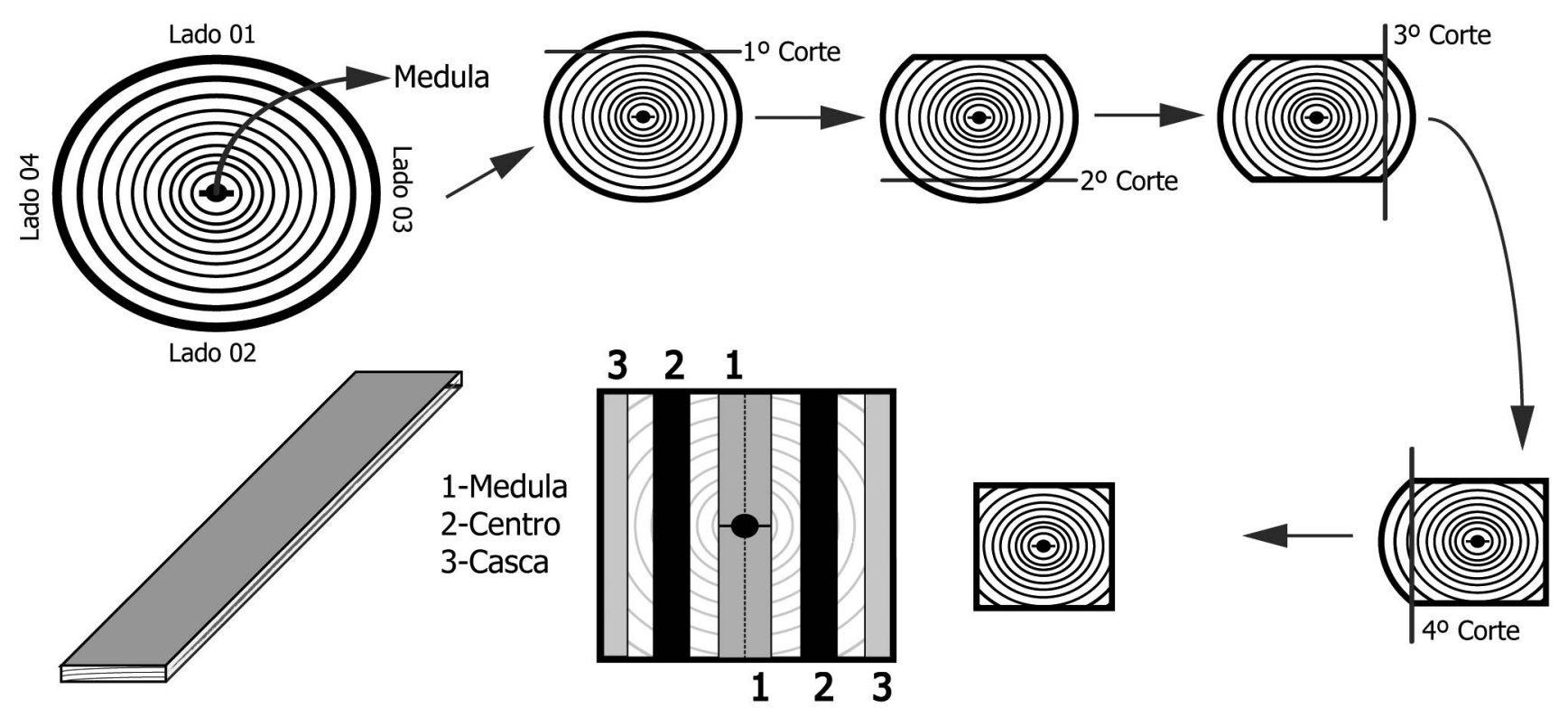

Figura 1. Esquema de desdobro das toras.

Todas as peças serradas foram cuidadosamente identificadas e estratificadas por tora, tendo-se o cuidado de mapear as suas posições espaciais de onde foram retiradas de cada tora. As tábuas foram separadas e medidas de acordo com sua posição relativa na tora e também na posição horizontal, ou seja, variação medulacasca, sendo utilizados três pontos de amostragem ao longo do raio da tora (Figura 1): 1 (medula), 2 (centro) e 3 (casca). As toras produziram de três a cinco tábuas, sendo adotado o seguinte critério para a avaliação dos três pontos: nas produções ímpares utilizou-se a peça do meio e as duas laterais, nas produções pares utilizou-se a média das duas centrais e as duas laterais, seguindo a metodologia desenvolvida por Lima et al. (2006).
As tábuas resultantes do desdobro no estado verde passaram por um processo de secagem natural. Estas foram tabicadas e ficaram armazenadas em um galpão com ventilação, por um período de quatro meses. Na avaliação das tábuas foi incorporado mais um tratamento, o COP2361D que se diferencia do COP2361 pela realização de desrama aos três anos de idade até a altura de $4 \mathrm{~m}$. Após o período de secagem foram feitas as seguintes avaliações:

\section{a) Índice de rachadura de extremidade de tábua seca (IRTS)}

Após secagem avaliou-se o IRTS das tábuas, que representa a média, na tora, dos comprimentos acumulados das rachaduras das duas extremidades de 
cada uma das tábuas no estado seco, sendo calculado pela equação 1 .

$$
\text { IRTS }=\frac{\sum_{i=1}^{n}\left(C_{1}+C_{2}\right)_{i}}{n}
$$

Em que: IRTS: índice de rachaduras de extremidade de tábua seca $(\mathrm{cm}) ; \mathrm{C}_{1}$ e $\mathrm{C}_{2}$ : comprimento das rachaduras respectivas das extremidades 1 e 2 das tábuas no estado seco $(\mathrm{cm})$; n: número de tábuas serradas obtidas da tora.

\section{b) Encurvamento}

De acordo com Lima et al. (2006), o encurvamento é utilizado para indicar o estado deformado de uma peça que sofreu flexão como consequência dos deslocamentos diferenciados que os pontos da peça sofreram em uma direção perpendicular às faces serradas.

\section{b1) Flecha de encurvamento $\left(F_{E}\right)$}

As flechas de encurvamento, medidas no comprimento real das tábuas, foram todas corrigidas para o comprimento padrão de $3 \mathrm{~m}$, usando a equação 2 .

$$
\mathrm{F}_{\mathrm{E}}=\mathrm{F}_{\mathrm{E}_{\mathrm{m}}}\left(\frac{\mathrm{L}_{\mathrm{P}}}{\mathrm{L}}\right)^{2}
$$

Em que: $\mathrm{F}_{\mathrm{E}}$ flecha de encurvamento da tábua, ajustada para um comprimento padrão Lp (tomado como sendo de $3 \mathrm{~m})(\mathrm{cm}) ; \mathrm{F}_{\mathrm{E}_{\mathrm{m}}}$ : flecha efetivamente medida na tábua $(\mathrm{cm}) ; \mathrm{L}=$ comprimento real da tábua $(\mathrm{m})$.

\section{c) Arqueamento}

$\mathrm{O}$ arqueamento surge pelo giro das seções transversais da peça em torno do seu eixo de maior inércia e, analogamente ao encurvamento, esse defeito surge em função da liberação das tensões residuais que existiam distribuídas ao longo da largura da peça (Lima et al., 2006).

\section{c1) Flecha de arqueamento $\left(F_{A}\right)$}

A flecha de arqueamento foi obtida de maneira similar a de encurvamento, sendo dada pela distância da borda deformada à borda virtual indeformada, medida na metade do comprimento da peça serrada. A flecha de arqueamento também foi ajustada para um comprimento padrão, através da equação 3 , similar a equação 2 .

$$
\mathrm{F}_{\mathrm{A}}=\mathrm{F}_{\mathrm{A}_{\mathrm{m}}}\left(\frac{\mathrm{L}_{\mathrm{P}}}{\mathrm{L}}\right)^{2}
$$

Em que: $\mathrm{F}_{\mathrm{A}}$ : flecha de arqueamento da tábua, ajustada para um comprimento padrão Lp, tomado como sendo de $3 \mathrm{~m}(\mathrm{~cm}) ; \mathrm{F}_{\mathrm{A}_{\mathrm{m}}}$ : flecha do maior arqueamento medida na tábua $(\mathrm{cm}) ; \mathrm{L}$ : comprimento real da tábua $(\mathrm{m})$.

\section{d) Quantidade de nós (N)}

Em cada uma das tábuas no estado seco foram contados os nós e calculado pela equação 4 , o valor médio por tora.

$$
N=\frac{\sum_{i=1}^{n}\left(l_{1}+l_{2}\right)_{i}}{n}
$$

Em que: N: número de nós; $1_{1}$ e $1_{2}$ : quantidade de nós em cada um dos respectivos lados das tábuas no estado seco; n: número de tábuas serradas obtidas da tora.

Inicialmente, foi efetuado o teste de homogeneidade de variância e para isso utilizou-se o teste de Hartley. Posteriormente, foi feito o teste $\mathrm{F}$ de análise de variância segundo o delineamento experimental inteiramente casualizado, adotando-se o esquema fatorial $13 \times 2 \times 3$ (clones, toras e posição radial). Foi aplicado o teste de Tukey, sempre que observada diferença significativa ao nível de 5\% de significância pelo teste $\mathrm{F}$. A análise estatística foi realizada pelo procedimento estatístico PROC GLM do SAS (SAS Institute Inc, 1999).

\section{Resultados e discussão}

Os resumos das análises de variância para as variáveis índice de rachaduras de extremidade de tábuas secas (IRTS), flecha de encurvamento $\left(\mathrm{F}_{\mathrm{E}}\right)$, flecha de arqueamento $\left(\mathrm{F}_{\mathrm{A}}\right)$ e quantidade de nós $(\mathrm{N})$ estão apresentados na tabela 2. Foram observadas diferenças significativas entre os clones e posição radial para todas as variáveis. Porém, para a posição da tora na altura da árvore não ocorreram diferenças significativas para as variáveis em estudo.

Os clones COP0477 e COP1404 apresentaram os maiores valores de IRTS e os clones COP1249, COP2361D e COP1406 os menores (Tabela 3). 
Tabela 2. Resumo da análise de variância efetuada para índice de rachaduras de extremidade de tábuas secas (IRTS), flecha de encurvamento $\left(\mathrm{F}_{\mathrm{E}}\right)$, flecha de arqueamento $\left(\mathrm{F}_{\mathrm{A}}\right)$ e quantidade de nós $(\mathrm{N})$.

\begin{tabular}{cccccc}
\hline & & \multicolumn{3}{c}{ Quadrado Médio } \\
\cline { 3 - 5 } Causa de Variação & GL & IRTS & $\mathbf{F}_{\mathbf{E}}$ & $\mathbf{F}_{\mathbf{A}}$ & $\mathbf{N}$ \\
\hline Clone (C) & 12 & $151^{* * *}$ & $1,40^{* *}$ & $0,87^{\text {**. }}$ & $38,83^{* * *}$ \\
Tora (T) & 1 & $6^{\text {n.s }}$ & $0,01^{\text {n.s. }}$ & $0,01^{\text {n.s. }}$ & $0,64^{\text {n.s. }}$ \\
C x T & 12 & $21^{\text {n.s. }}$ & $0,39^{\text {n.s. }}$ & $0,34^{\text {n.s. }}$ & $10,54^{\text {n.s. }}$ \\
Posição radial (P) & 2 & $5317^{* *}$ & $2,55^{* *}$ & $1,14^{* *}$ & $1249,48^{* *}$ \\
C x P & 24 & $63^{\text {n.s. }}$ & $0,41^{\text {n.s. }}$ & $0,14^{\text {n.s. }}$ & $9,70^{\text {n.s. }}$ \\
T x P & 2 & $17^{\text {n.s. }}$ & $0,21^{\text {n.s. }}$ & $0,01^{\text {n.s. }}$ & $8,17^{\text {n.s. }}$ \\
C x T x P & $18^{\text {n.s. }}$ & $0,26^{\text {n.s. }}$ & $0,21^{\text {n.s. }}$ & $4,30^{\text {n.s. }}$ \\
Resíduo & 24 & 35 & 0,28 & 0,29 & 6,22 \\
\hline Média & 231 & 10,08 & 1,31 & 1,01 & $(\mathrm{~cm})$ \\
\hline
\end{tabular}

Onde: ** significativo ao nível de $1 \%$ de significância pelo teste $\mathrm{F} ; \mathrm{n} . \mathrm{s}=$ não significativo

Tabela 3. Índice de rachaduras de extremidade de tábuas secas (IRTS), flecha de encurvamento $\left(\mathrm{F}_{\mathrm{E}}\right)$, flecha de arqueamento $\left(\mathrm{F}_{\mathrm{A}}\right)$ e quantidade de nós $(\mathrm{N})$ de clones de Eucalyptus spp. e E. cloeziana.

\begin{tabular}{ccccc}
\hline Tratamentos & $\begin{array}{c}\text { IRTS } \\
(\mathbf{c m})\end{array}$ & $\begin{array}{c}\left(\mathbf{F}_{\mathbf{E}}\right) \\
(\mathbf{c m})\end{array}$ & $\begin{array}{c}\left(\mathbf{F}_{\mathbf{A}}\right) \\
(\mathbf{c m})\end{array}$ & $\mathbf{N}$ \\
\hline COP1277 & $11,1^{\mathrm{abc}}$ & $1,10^{\mathrm{b}}$ & $1,10^{\mathrm{abc}}$ & $4,38^{\mathrm{d}}$ \\
COP1249 & $6,8^{\mathrm{c}}$ & $1,19^{\mathrm{b}}$ & $0,99^{\mathrm{abc}}$ & $6,72^{\mathrm{bcd}}$ \\
COP1341 & $11,0^{\mathrm{abc}}$ & $1,24^{\mathrm{b}}$ & $1,26^{\mathrm{a}}$ & $7,98^{\mathrm{abc}}$ \\
COP2361 & $8,4^{\mathrm{bc}}$ & $1,12^{\mathrm{b}}$ & $0,78^{\mathrm{abc}}$ & $7,26^{\mathrm{abc}}$ \\
COP2361D & $6,8^{\mathrm{c}}$ & $1,19^{\mathrm{b}}$ & $0,99^{\mathrm{abc}}$ & $6,73^{\mathrm{bcd}}$ \\
COP0477 & $14,8^{\mathrm{a}}$ & $1,31^{\mathrm{b}}$ & $1,07^{\mathrm{abc}}$ & $7,09^{\mathrm{bc}}$ \\
COP7490 & $11,3^{\mathrm{abc}}$ & $1,23^{\mathrm{b}}$ & $1,19^{\mathrm{ab}}$ & $6,95^{\mathrm{bc}}$ \\
COP0321 & $9,3^{\mathrm{abc}}$ & $1,28^{\mathrm{b}}$ & $1,09^{\mathrm{abc}}$ & $6,54^{\mathrm{cd}}$ \\
COP1404 & $14,1^{\mathrm{ab}}$ & $1,53^{\mathrm{ab}}$ & $1,12^{\mathrm{abc}}$ & $7,63^{\mathrm{abc}}$ \\
COP1406 & $7,5^{\mathrm{c}}$ & $1,44^{\mathrm{b}}$ & $0,65^{\mathrm{c}}$ & $9,66^{\mathrm{a}}$ \\
COP1296 & $10,7^{\mathrm{abc}}$ & $1,54^{\mathrm{ab}}$ & $0,89^{\mathrm{abc}}$ & $7,76^{\mathrm{abc}}$ \\
COP0520 & $9,8^{\mathrm{abc}}$ & $1,98^{\mathrm{a}}$ & $0,71^{\mathrm{bc}}$ & $9,12^{\mathrm{ab}}$ \\
E. cloeziana & $8,6^{\mathrm{bc}}$ & $1,06^{\mathrm{b}}$ & $1,21^{\mathrm{ab}}$ & $6,81^{\mathrm{bc}}$ \\
$1^{\mathrm{a}}$ Tora & $10,16^{\mathrm{a}}$ & $1,33^{\mathrm{a}}$ & $1,00^{\mathrm{a}}$ & $7,31^{\mathrm{a}}$ \\
$2^{\mathrm{a}}$ Tora & $9,87^{\mathrm{a}}$ & $1,31^{\mathrm{a}}$ & $1,01^{\mathrm{a}}$ & $7,21^{\mathrm{a}}$ \\
Medula & $17,71^{\mathrm{a}}$ & $1,10^{\mathrm{b}}$ & $1,13^{\mathrm{a}}$ & $10,71^{\mathrm{a}}$ \\
Centro & $9,17^{\mathrm{b}}$ & $1,40^{\mathrm{a}}$ & $0,99^{\mathrm{ab}}$ & $7,39^{\mathrm{b}}$ \\
Casca & $3,39^{\mathrm{c}}$ & $1,42^{\mathrm{a}}$ & $0,91^{\mathrm{b}}$ & $3,78^{\mathrm{c}}$ \\
\hline
\end{tabular}

Onde: Médias seguidas de letras diferentes em uma mesma coluna diferem entre si (ao nível de 5\% de significância).

A grande variabilidade observada entre os clones para as rachaduras pode ser explicada segundo vários autores, pelo controle de fatores genéticos dos materiais (Cl) (Fernandes, 1986; Malan \& Hoon, 1992; Schacht et al., 1998). Pode-se considerar que os clones que apresentaram rachaduras menores que $10 \mathrm{~cm}$ como tendo mais potencial para uso como madeira serrada.

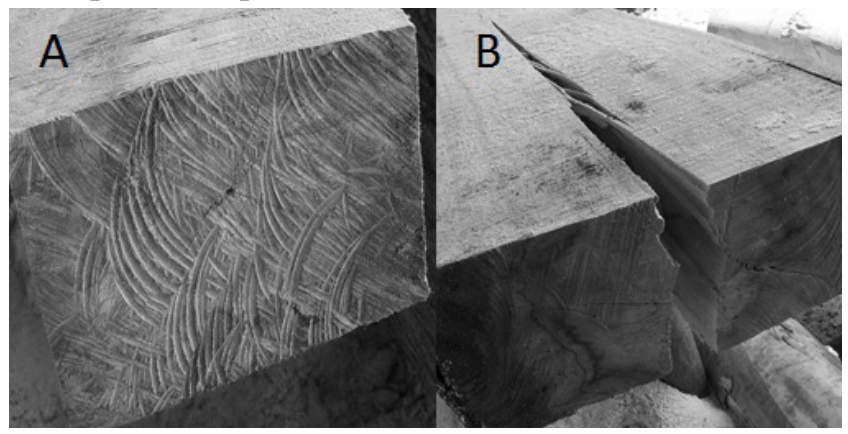

Figura 2. A) Clone com baixa intensidade de rachaduras; B) Clone com alta intensidade de rachaduras.

As $1^{\text {as }}$ e $2^{\text {as }}$ toras apresentaram valores semelhantes de rachaduras (Tabela 3). Isso ocorreu, muito provavelmente, pela pequena diferença entre seus diâmetros. Segundo Kubler (1987), quanto menor o diâmetro das toras, maior o nível de tensões internas que se manifestam em forma de rachaduras durante o desdobro e a secagem das tábuas. Resultados semelhantes foram obtidos por Lima et al. (2000), Santos et. al. (2004), Lima \& Garcia (2008), Carvalho et al. (2010) e Souza et. al. (2012). Entretanto, Miranda \& Nahuz (1999) obtiveram valores significativamente diferentes de IRTS, sendo $2,87 \%$ e $2,05 \%$, respectivamente, para a posição superior e base.

Foi observado também que as rachaduras diminuíram significativamente no sentido da medula para casca (Tabela 3). De acordo com Kubler (1987), Garcia (1995) e Lima et al. (2006), nas tábuas da região próxima à 
medula ocorre um efeito combinado de dois fatores importantes: o primeiro deles é que a madeira central, por ser predominantemente composta de madeira juvenil, apresenta menor resistência à tração normal das fibras, e o segundo é que as componentes transversais originárias da tensão de crescimento longitudinal, quando liberadas no desdobro, são as máximas possíveis e coincidem com a direção paralela às faces, provocando, portanto, tração normal máxima. Assim, a madeira da região próxima da medula apresenta menor resistência aos efeitos das tensões de crescimento e tensões de secagem.

Para a flecha de encurvamento $\left(\mathrm{F}_{\mathrm{E}}\right)$ foi observado que, de maneira geral, todos os materiais apresentaram baixos valores de encurvamento, podendo destacar $E$. cloeziana que apresentou o menor valor enquanto o clone COP0520 maior valor. Destacamos também a grande variabilidade observada entre os clones (Tabela 3 ).

$\mathrm{O}$ encurvamento das $1^{\text {as }}$ e $2^{\text {as }}$ toras não diferiram significativamente entre si (Tabela 3). Resultado diferente foi obtido por Del Menezzi \& Nahuz (1998) e Lima et al. (2006) que verificaram que o encurvamento das tábuas em estado verde das $2^{\text {as }}$ toras foram superiores aos das $1^{\text {as }}$. De acordo com Kubler (1987) quanto menor o diâmetro das toras, maior o nível de tensões internas que se manifestam também na forma de encurvamento durante o desdobro e secagem das tábuas.

Pode-se observar que ocorreu uma tendência de aumento do encurvamento no sentido medula-casca (Tabela 3). Ressaltamos que o momento liberado perde intensidade na direção paralela às faces e adquire maior importância na direção perpendicular às faces à medida que se segue para a periferia da tora. Dessa forma, a energia de deformação que provoca rachadura vai se transformando gradativamente em energia de deformação, que provoca encurvamento. Portanto, as tábuas oriundas da região próxima à casca estão mais propensas ao encurvamento consequente das tensões de crescimento e tensões de secagem.

Com relação a flecha de arqueamento $\left(\mathrm{F}_{\mathrm{A}}\right)$ os materiais, de maneira geral, apresentaram baixos valores e pouca variabilidade entre os clones, podendo-se destacar o COP1406 que apresentou o menor valor de arqueamento (Tabela 3). A pouca variabilidade observada entre os clones, segundo Lima et. al. (2006), ocorre devido a esse defeito não aparecer quando a estratégia de desdobro adotada produz liberação de tensões residuais de forma equilibrada. Para o esquema de desdobro adotado, somente ocorreria arqueamento mais acentuado nas tábuas se houvesse alguma excentricidade natural na tora, dada pelo deslocamento de medula, ou alguma excentricidade operacional na serra, dada por um corte assimétrico causado por um erro de posicionamento da tora na alimentação da serra. Isso também foi notado por Rocha \& Trugilho (2006) que verificaram baixos valores de arqueamento em tábuas obtidas por corte na serra múltipla.

Para flecha de arqueamento, as $1^{\text {as }}$ e $2^{\text {as }}$ tora não apresentaram diferenças significativas entre si. Souza et. al. (2012) verificaram uma diminuição no arqueamento das tábuas proveniente de arvores de maiores diâmetros. Sendo, então, as dominantes classificadas como superiores no processo de secagem. Entretanto, no sentido da medula para casca verifica-se uma diminuição do arqueamento (Tabela 3 ).

Com relação ao número de nós, pode-se verificar que o COP1277 apresentou o menor número e o COP1406 o maior (Tabela 3). Isso pode ser devido à característica de desrama natural que esses materiais apresentam. Entretanto, de maneira geral, todos os materiais analisados apresentaram alta incidência de nós por tábua, o que influencia negativamente na qualidade. Observa-se que a desrama efetuada no clone COP2361D foi provavelmente tardia, pois não foi tão eficiente no sentido de diminuir significativamente o número de nós por tábua. Resultados semelhantes foram obtidos por Bredenkamp et al. (1980), que não observaram diferenças significativas entre tratamentos com e sem desrama na produção de madeira limpa em árvores de $E$. grandis, na África do Sul. Polli et al. (2006) verificaram em populações clonais de E. grandis que maior extensão de madeira limpa, menores valores de núcleo nodoso e menor extensão da oclusão dos galhos são observados em ferimentos provocados pela remoção dos mesmos em árvores de menor diâmetro, indicando que esses devem ser removidos o mais cedo possível, enquanto o seu diâmetro ainda for reduzido. Esses autores também indicam a necessidade de seleção de material genético que apresente galhos mais finos até a altura da tora a ser aproveitada para serraria, e que a operação de desrama artificial seja realizada o mais cedo possível para obtenção de maior extensão de madeira limpa.

De maneira geral, pode-se verificar que esses materiais apresentaram boa qualidade na maioria das características avaliadas. Temos que considerar que E. cloeziana apresenta idade mais avançada do que os outros materiais (22 anos) e o COP1249 merece 
destaque, pois aos 8 anos apresentou características com potencial para usos para processamento mecânico em quase todas as avaliações. O COP0520 não pode ser devidamente avaliado, dado sua menor idade e diâmetro. Deve-se considerar a hipótese de testar esses materiais com idade mais avançada.

\section{Conclusões}

Verificou-se diferença entre clones e posição radial para o índice de rachaduras de extremidade de tábuas secas (IRTS), flecha de encurvamento $\left(\mathrm{F}_{\mathrm{E}}\right)$, flecha de arqueamento $\left(\mathrm{F}_{\mathrm{A}}\right)$ e quantidade de nós $(\mathrm{N})$. Para posição da tora na altura da árvore não ocorreu diferença entre clones. Todos os clones apresentaram baixos valores de encurvamento e arqueamento e alta incidência de nós.

Os clones que apresentaram rachaduras menores que $10 \mathrm{~cm}$ foram considerados como potenciais para serraria.

A rachadura de tábua seca, $\mathrm{o}$ arqueamento e o número de nós diminuem no sentido medula-casca, mas o encurvamento tende a aumentar no mesmo sentido.

\section{Referências}

Apolo11.com. Latitude e longitude das cidades brasileiras: Bahia. Disponível em: $<$ http://www.apolo11.com/latlon.php?uf=ba $>$ Acesso em: 4 maio 2016.

Bredenkamp, B. V. et al. Some effects of pruning on growth and timber quality of Eucalyptus grandis in Zululand. South African Forestry Journal, v. 114, p. 29-34, 1980.

Carvalho, A. M. et al. Correlações da altura e diâmetro com tensões de crescimento em árvores de Corymbia citriodora e Eucalyptus urophylla. Revista Árvore, v. 34, n. 2, p. 323-331, 2010.

Del Menezzi, C. H. S. \& Nahuz, M. A. R. Comportamento de Eucalyptus grandis [Hill ex Maiden] no desdobro. Revista Árvore, v. 22 , n. 4 , p. 563-571, 1998.

Dinwoodie, J. M. Growth stresses in timber: a review of literature. Forestry, v. 39, n. 2, p. 162-170, 1966.

Duque Silva, L. et al. Desafios do uso da madeira de Eucalyptus benthamii para serraria. In: Duque Silva, L. et al. Silvicultura e melhoramento genético de Eucalyptus benthamii. Curitiba: FUPEF, 2012. v. 1.140 p.

Fernandes, P. S. Tensões de crescimento em progênies de Eucalyptus urophylla. Boletim Técnico do Instituto Florestal, v. 40A, n. 2, p. 616-38, 1986.

Freitas, A. R. \& Brito Neto, O. Os avanços tecnológicos no processamento e uso de produtos florestais: produção de madeira serrada de eucalipto. In: CONGRESSO FLORESTAL BRASILEIRO, 7. Curitiba, 1993. Anais. Curitiba: SBS; SBEF, 1993. v. 3, p. 293-295.
Garcia, J. N. Técnicas de desdobro de eucalipto. In: SEMINÁRIO INTERNACIONAL DE UTILIZAÇÃO DA MADEIRA DE EUCALIPTO PARA SERRARIA, 1995, São Paulo, IPEF/IPT, Anais... São Paulo: IPEF/IPT, 1995. p. 1-19.

Jacobs, M. R. The growth stresses of wood stems. Commonwealth Forestry Burean, n. 28, p. 1-67, 1945.

Kubler, H. Growth stresses in trees and related wood properties. Forestry Abstracts, v. 48, p. 131-189, 1987.

Lima, I. L. et al. Efeito do desbaste e da fertilização nas tensões de crescimento e peças serradas de dimensões comerciais em Eucalyptus grandis. Scientia Forestalis, v. 70, p. 171-183, 2006.

Lima, I. L. \& Garcia, J. N. Influência do desbaste e da fertilização nos índices de rachamento após desdobro e secagem em madeira serrada de Eucalyptus grandis Hill ex-Maiden. Revista do Instituto Florestal, v. 20, p. 175-184, 2008.

Lima, I. L. et al. Influência do desbaste nas tensões de crescimento de E. grandis Hill ex-Maiden. Scientia Forestalis, n. 58, p. 111$125,2000$.

Malan, F. S. \& Hoon, M. Effect of initial spacing and thinning on some wood properties of Eucalyptus grandis. South African Forestry Journal, n. 163, p. 13-20, 1992. DOI: 10.1080/00382167.1992.9629362.

Miranda, M. J. A. C. \& Nahuz, M. A. R. Estudo da influência do espaçamento de plantio de Eucalyptus saligna Smith nos índices de rachamento após o desdobro e após a secagem. Scientia Forestalis, n. 55, p. 107-116, 1999.

Opie, J. E. et al. Stand management. In: Hillis, W. \& Brown, A. G. Eucaliptos for wood production. Melbourne: CSIRO, 1984. 434 p.

Ponce, R. H. Madeira serrada de eucalipto: desafios e perspectivas. In: SEMINÁRIO INTERNACIONAL DE UTILIZAÇÃO DA MADEIRA DE EUCALIPTO PARA SERRARIA, Piracicaba: IPEF/ IPT, 1995. p. 50-58.

Polli, H. Q. et al. Qualidade da madeira em clone de Eucalyptus grandis W. Hill ex Maiden submetido a desrama artificial. Revista Árvore, v. 30, n. 4, p. 557-566, 2006. DOI: 10.1590/S010067622006000400008 .

Rocha, M. P. \& Trigilho, P. F. Qualidade de madeira serrada de Eucalyptus dunnii em função do método de desdobro e condição de umidade. Cerne, v. 12, n. 4, p. 314-21, 2006.

Santos, P. E. T. et al. Estimates of genetic parameters of wood traits for sawn timber production in Eucalyptus grandis. Genetics and Molecular Biology, v. 27, n. 4, p. 567-573, 2004. DOI: 10.1590/ S1415-47572004000400017.

SAS Institute Inc. SAS Procedures guide: version 8 (TSMO). Cary, N.C., 1999.

Schacht, L. et al. Variação genética de indicadores de tensão de crescimento em clones de Eucalyptus urophylla. Scientia Forestalis, n. 54, p. 55-68, 1998.

Souza, J. T. et al. Qualidade da madeira serrada proveniente de árvores dominantes e médias de Eucalyptus grandis submetidas à secagem. Cerne, v. 18, n. 1, p. 167-174, 2012. DOI: 10.1590/S010477602012000100020 . 
Van Wyk , J. L. Hardwood sawmilling can have a bright future in South Africa. South African Forestry Journal, n. 107, p. 47-53, 1978. DOI: $10.1080 / 20702620.1978 .10433505$.
Viana, L. O. Experiência do SENAI/CETMAN com secagem de eucalipto. In: SEMINÁRIO SOBRE PROCESSAMENTO E UTILIZAÇÃO DE MADEIRAS DE REFLORESTAMENTO, 4. Curitiba, 1996. Anais... Curitiba: ABPM, 1996. p. 119-130. 